\title{
Rancang Bangun Sistem Informasi Tempat Pemakamam Umum Pondok Rajeg Bogor Berbasis Web
}

\author{
Ibnu Rusdi ${ }^{1}$, Indra Febria Widy ${ }^{2}$,Hiysam Husein ${ }^{3}$ \\ ${ }^{1}$ STMIK Nusa Mandiri Jakarta \\ e-mail: irusyd19@gmail.com, \\ Sekolah Tinggi Teknik Cendekia \\ e-mail : indra.febria@cendekia.ac.id \\ ${ }^{2}$ Universitas Bina Sarana Informatika \\ e-mail: hisy4m.husein@gmail.com
}

\begin{abstract}
The use of information technology has a very broad scope. One of them is in the field of funeral. Funeral is often a "backward" issue in this life. Even if we look at our "nature" as human beings, we will all experience what is called death. The thing we need to prepare for death besides worship is that we need to prepare our final rest right. We often forget this, even though if we see the phenomenon that the world mortality rate is increasing every day, even Indonesia is one of the countries with a very high mortality rate. The high mortality rate is not in line with the number of locations or burial places available. This has become a problem that must be solved and become a problem that is quite serious and needs serious handling. One of the solutions to this problem is the use of information technology to record the overall mortality rate and also record the availability of existing locations to bury it. That way the government can monitor every problem that exists and can provide solutions that can be disseminated easily by utilizing information technology, the author uses the Waterfall method to facilitate the process of needs analysis until testing the design of building information systems public cemetery (TPU) Pondok Rajeg Bogor.
\end{abstract}

Keywords: Information System, Waterfall, TPU Pondok Rajeg

\section{PENDAHULUAN}

Pada era globalisasi seperti saat ini, perkembangan teknologi semakin hari menunjukan peningkatan yang sangat pesat. Perkembangan tersebut dipicu karena semakin besarnya kebutuhan akan teknologi untuk membantu dalam menjalankan kehidupan sehari-hari. Perkembangan teknologi kini telah meyentuh berbagai kalangan masyarakat didunia. Baik dewasa, remaja maupun anak-anak telah mengenal teknologi. Bahkan tanpa disadari ketika mengawali aktivitas, dimulai dipagi hari hingga malam hari setiap manusia bersentuhan dengan teknologi baik secara langsung maupun secara tidak langsung. Dewasa ini peran teknologi telah mnggantikan peran manusia dalam menjalankan kehidupanya.

Perkembangan teknologi yang sangat terasa saat ini adalah perkembangan teknologi pada bidang informasi. "Internet", kata tersebut akhir-akhir ini menjadi salah satu "penyebab" utama yang "mengakibatkan" seluruh orang dunia dapat berinteraksi dengan mudahnya. Jangkauannya yang tidak terbatas menjadikan masyarakat "berbondongbondong" untuk mengenal dan mempelajari penggunaannya. Karena dengan penggunaan internet kita dapat bertukar informasi dengan sangat mudah dan dalam waktu yang sangat cepat.

Pemanfaatan teknologi informasi memiliki cangkupan yang sangat luas,. Salah satunya adalah dalam bidang pemakaman. Pemakaman sering menjadi isu "terbelakang" dalam kehidupan ini. Padahal jika kita melihat "kodrat" kita sebagai manusia kita semua akan mengalami apa yang dinamakan dengan kematian. Hal yang perlu kita persiapkan menuju kematian selain amal ibadah adalah kita perlu mempersiapkan tepat peristirahatan terakhir kita. Angka kematian yang tinggi tersebut tidak seiring dengan jumlah lokasi atau tempat pemakaman yang tersedia. Menurut Tukiman dalam (Frieyadie \& Kristiana, 2016) Ahli waris atau masyarakat tidaklah mengetahui apakah kerabat yang dikubur masih terdata atau tidak, atau memamg sudah ditumpang dengan jenazah yang Hal tersebut menjadi permasalahan yang harus dipecahkan dan menjadi masalah yang cukup serius dan perlu penanganan yang serius pula. Dari rasio yang ada peningkatan jumlah penduduk pada suatu wilayah akan berdampak pada jumlah kematian serta jumlah kebutuhan lahan yang tersedia (Sofian, 2015). Dengan begitu pemerintah dapat memantau setiap permasalahan yang ada dan dapat memberikan solusi yang dapat disebarluaskan dengan mudah 
dengan memanfaatkan teknologi informasi yang telah dibangun. Dalam data resmi oleh UPT Pemakaman DKP Kota Depok, dominasi penumpukan jenazah dalam satu liang lahat terjadi di TPU Kalimulya I, II, III, TPU Cimpaeun, dan TPU Tapos dimana daya tampungnya sudah over kapasitas. (Friyadie \& Kristiana, 2016).

Tempat Pemakaman Umum Pondok Rajeg salah satu tempat yang menyediakan lokasi untuk memakamkan di kota Bogor. Dimana Tempat Pemakaman Umum Pondok Rajeg tersebut beralamat di J1. Pondok Rajeg Kecamatan Ujung Berung Kelurahan Pasir Jati Kota Bogor.

Penulis mengidentifikasi beberapa permasalahan yang ditemukan dilapangan selama melakukan observasi diantaranya adalah :

1. Proses pendaftaran pemakaman masih terkendala terhadap ketersediaan lahan yang tidak diketahui oleh pendaftar.

2. Proses pemetaan kavling mengalami kesulitan karena belum terdata dengan baik antara luas lahan yang tersedia dengan perkiraan jumlah makam yang dapat ditampung.

3. Proses pembayaran pajak tahunan terdapat kesulitan untuk mencari data jenazah yang dalam masa tenggang pembayaran pajak.

4. Proses penumpukan jenazah mengalami kesulitan karena tidak adanya data jenazah berdasarkan ikatan keluarganya.

\section{METODOLOGI PENELITIAN}

Penulisan artikel ini penulis menggunakan beberapa metode penelitian yaitu :

1. Metode Observasi

Yaitu melakukan pengamatan terhadap sejumlah objek penelitian untuk mengumpulkan data dan informasi yang berkaitan dengan permasalahan yang ada.

2. Metode Studi Pustaka

Metode pengumpulan data yang didapat dari berbagai sumber, jurnal, internet, dan pustaka sebagai acuan penulisan.

Medote dalam pengembangan perangkat lunak yaitu Model SDLC air terjun (waterfall) sering juga disebut model sekuensial (sequential linear) atau alur hidup klasik (classic life cycle). Model air terjun menyediakan pendekatan alur hidup perangkat lunak secara sekuensial atau terurut dimulai dari desain, pengkodean, pengujian, dan tahap pendukung (support) (Rosa \& Shalahuddin, 2013)

1. Analisis Kebutuhan

Proses pengumpulan kebutuhan dilakukan secara intensif untuk mespesifikasikan kebutuhan perangkat lunak agardapat dipahami perangkat lunak yang seperti apa dibutuhkan oleh user. Spesifikasi kebutuhan perangkat lunak pada tahap ini perlu untuk didokumentasikan.

2. Desain

Desain perangkat lunak adalah proses multi langkah yang fokus pada desain pembuatan program perangkat lunak, representasi antarmuka, dan prosedur pengkodean. Tahap ini mentranslasi kebutuhan perangkat lunak dari tahap analsis kebutuhan ke representasi desain agar dapat diimplementasikan menjadi program pada tahap selajutnya. Desain perangkat yang dihasilkan pada tahap ini juga perlu didokumentasikan.

3. Pembuatan Kode Program

Desain harus ditansikan kedalam program perangkat lunak. Hasil dari tahap ini adalah program komputer sesuai dengan desain yang telah dibuat pada thap desain.

4. Pengujian

Pengujian fokus pada perangkat lunak secara dari segi logik dan fungsional dan memastikan bahwa semua bagian sudah diuji. Hal ini dilakukan untuk meminimalisirkan kesalahan (eror) dan memastikan keluaran yang dihasilkan sesuai dengan yang diinginkan.

Menurut (Sibero, Alexander F, 2013)"World Wide Web (W3) atau dikenal dengan istilah web adalah suatu sistem yang berkaitan dengan dokumen digunakan sebagai media untuk menampilkan teks, gambar, multimedia dan lainnya pada jaringan internet". Menurut (Sibero, Alexander F, 2013)“Hyper Text Markup Languange (HTML) adalah bahasa yang digunakan pada dokumen web sebagai bahasa untuk pertukaran dokumen web. Struktur dokumen HTML terdiri tag pembuka dan tag penutup".

PHP adalah pemprograman interprenter yaitu proses penerjemah baris kode sumber menjadi kode mesin yang dimengerti komputer secara langsung pada saat baris kode dijalankan, suatu bahasa dengan hak cipta terbuka atau yang juga dikenal dengan istilah Open Source mengembangkan kode-kode fungsi PHP (Sibero, Alexander F, 2013). Sedangkan menurut (Kadir, 2005)“Javascript adalah bahasa script yang biasa diletakkan bersama kode HTML untuk menentukan suatu aksi".

JQuery adalah salah satu javascript framework yang memiliki ciri khas pada penggunaan perintahnya, prefix untuk jQuery dengan tanda \$ kemudian dilanjutkan dengan fungsi atau perintah untuk mempermudah merancang penyusunan pada file (Sibero, Alexander F, 2013)

\section{HASIL DAN PEMBAHASAN}

Pada perancangan sistem ini dimana penulis melakukan penggambaran terhadap sistem yang akan dibangun untuk membantu memaksimalkan kinerja dari TPU. Proses perancangan itu sendiri dilakukan setelah kita melakukan observasi secara 
langsung dan melakukan analisis kebutuhan sistem yang akan dibangun. Perancangan sistem ditujukan agar dapat mempermudah dalam proses pembangunan sistem, dimana hal tersebut dilakukan dengan menggambarkan alur kerja yang akan dibangun berdasarkan kebutuhan yang telah dianalisis. Pada sistem yang diusulkan ini pengguna sistem dapat dibagi kedalam 2 (dua) jenis, yaitu sebagai berikut:

1. Staff TPU

a) Staf merupakan bagian yang mengelola segala kegiatan dalam menyediakan lahan untuk pemakaman jenazah.

b) Selain itu juga staf bertugas untuk melayani kebutuhan akan lahan pemakaman jenazah.

2. Ahli Waris

a) Ahli waris merupakan orang yang melakukan pendaftaran terhadap jenazah yang akan dimakamkan,

b) ahli waris bertanggung jawab akan pemakaman jenazah yang didaftarkan dalam hal perawatan dan pengelolaan makam.

A. Rancangan Antar Muka

Penulis akan memberikan gambaran tentang website yang akan dibuat yaitu mengenai spesifikasi rancangan website yang nantinya dibuat untuk memudahkan para pengunjung yang menggunakan internet untuk mengetahui informasi apa saja yang ada di TPU pondok rajeg.

1. Rancangan Antar Muka Halaman Utama / Index

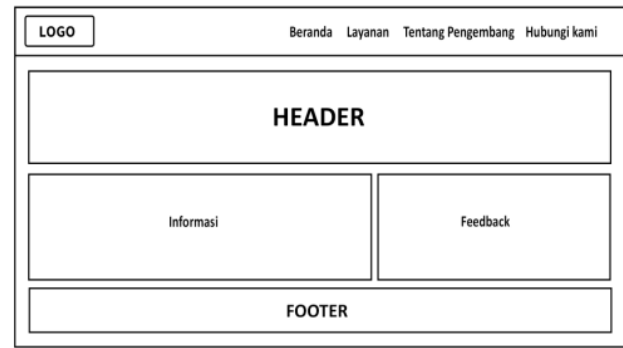

Gambar 1. Rancangan Halaman Utama

2. Rancangan Antar Muka Halaman Menu Layanan

\begin{tabular}{|c|c|c|}
\hline LOGO & Beranda Layanan & Tentang Pengembang Hubungi kami \\
\hline GAMBAR & GAMBAR & GAMBAR \\
\hline TEKS & TEKS & TEKS \\
\hline SELANJUTNYA & SELANJUTNYA & SELANJUTNYA \\
\hline
\end{tabular}

Gambar 2. Rancangan Halaman Layanan
3. Rancangan Antar Muka Halaman Tentang Pengembang

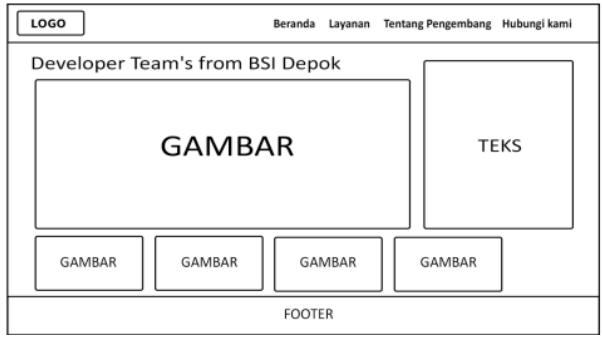

Gambar 3. Rancangan Halaman Tentang Pengembang

4. Rancangan Antar Muka Halaman Hubungi Kami

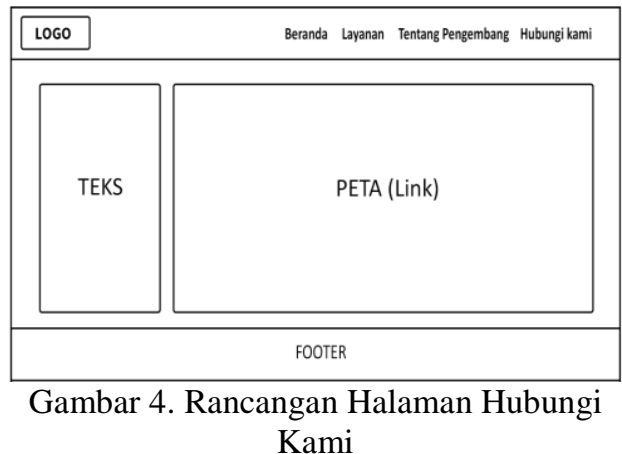

5. Rancangan Antar Muka Halaman Prosedur Pendaftaran

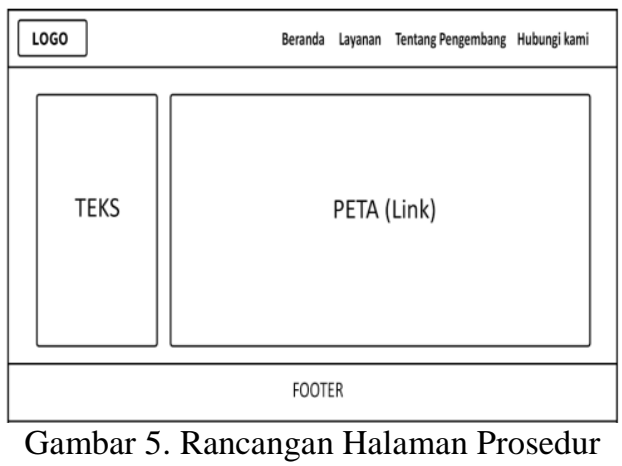
Pendaftaran

6. Rancangan Antar Muka Halaman Input Data Ahli Waris

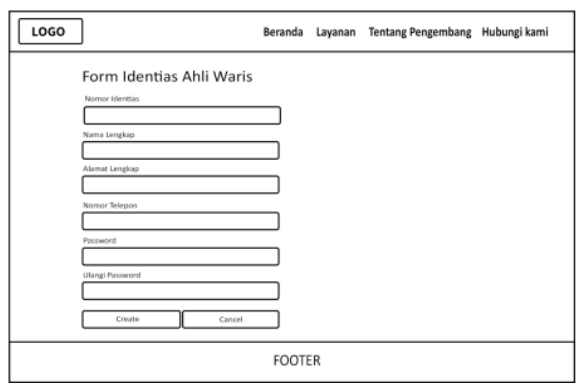

Gambar 6. Rancangan Halaman Input Data Ahli Waris 
7. Rancangan Antar Muka Halaman Login Ahli Waris

\begin{tabular}{|c|c|}
\hline 1060 & Beranda Layanan Tentang Pengembang Hubungi kami \\
\hline \multicolumn{2}{|r|}{ Login Ahli Waris } \\
\hline & \\
\hline & 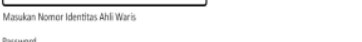 \\
\hline & $\left.\right|^{2}$ \\
\hline & $\operatorname{sint}$ \\
\hline \multicolumn{2}{|r|}{ Focteph } \\
\hline
\end{tabular}

Gambar 7. Rancangan Halaman Login Ahli Waris

B. Rancangan Basis Data

Rancangan Basis Data menghasilkan pemetaan tabel-tabel yang digambarkan dengan Entity Relationship Diagram (ERD), Logic Record Structure (LRS) dan Spesifikasi File.

1. Entity Relationship Diagram

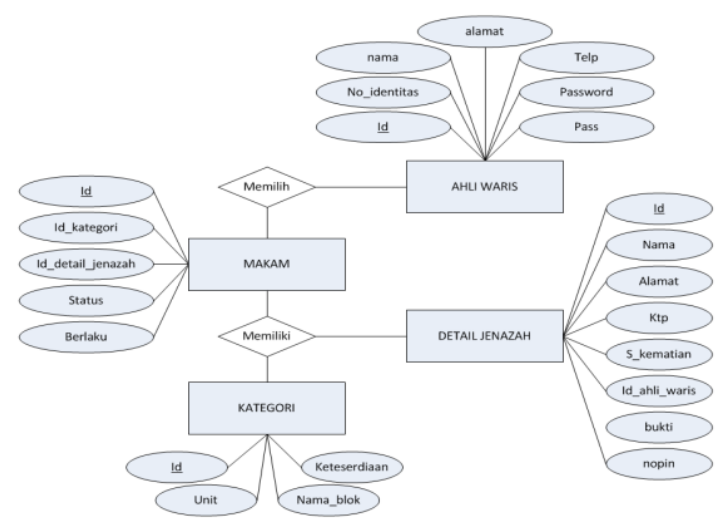

Gambar 8. Entity Relationship Diagram (ERD)

2. LRS (Logical Record Structure)

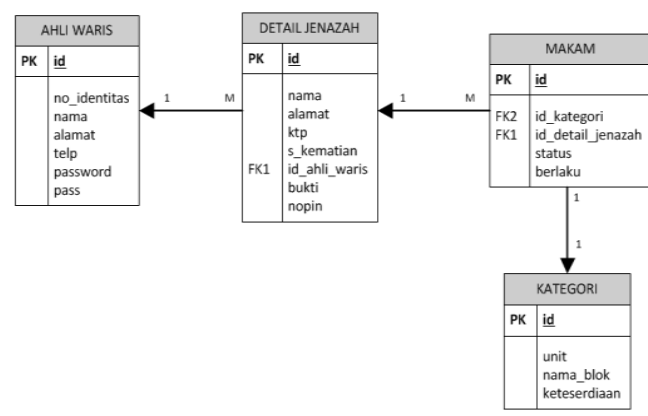

Gambar 9. Logical Record Structure (LRS)
3. Spesifikasi File

a. Detail Jenazah

Nama File : Detail Jenazah

Akronim : detail_jenazah.sql

Fungsi : Untuk Melihat dan

Mengelola Data Jenazah

Organisasi File : Index Sequential

Media : Hardisk

Panjang Record : 478 Byte

Kunci Field : id

Software : Mysql

Tabel 1. Spesifikasi Detail Jenazah

\begin{tabular}{llcl}
\hline Akronim & Tipe & Panjang & Ket \\
\hline id & Integer & 11 & PK \\
\hline nama & Varchar & 25 & \\
\hline no_identitas & Varchar & 20 & \\
\hline alamat & Varchar & 100 & \\
\hline ktp & Varchar & 100 & \\
\hline s_kematian & Varchar & 100 & \\
\hline $\begin{array}{l}\text { id_ahli_wari } \\
\text { s }\end{array}$ & Integer & 11 & \\
\hline bukti & Varchar & 100 & \\
\hline nopin & Integer & 11 & \\
\hline Sumber: Hasil Penelitian $(2019)$
\end{tabular}

Sumber: Hasil Penelitian (2019)

b. Ahli Waris

$\begin{array}{ll}\text { Nama File } & : \text { Ahli Waris } \\ \text { Akronim } & : \text { ahli_waris.sql } \\ \text { Fungsi } & : \text { Untuk Melihat dan } \\ & \text { Mengelola Data Ahli } \\ & \text { Waris Jenazah } \\ \text { Tipe File } & : \text { File Master } \\ \text { Organisasi File } & : \text { Index Sequential } \\ \text { Media } & : \text { Hardisk } \\ \text { Panjang Record } & : \text { 630 Byte } \\ \text { Kunci Field } & : \text { id } \\ \text { Software } & : \text { Mysql }\end{array}$

Tabel 2. Spesifikasi File Ahli Waris

\begin{tabular}{llcc}
\hline Akronim & Tipe & Panjang & Ket \\
\hline id & Integer & 11 & PK \\
\hline username & Varchar & 32 & \\
\hline password & Varchar & 255 & \\
\hline $\begin{array}{l}\text { nama_admi } \\
\text { n }\end{array}$ & Varchar & 25 & \\
\hline telp & Varchar & 20 & \\
\hline password & Varchar & 255 & \\
\hline pass & Varchar & 32 & \\
\hline
\end{tabular}

Sumber: Hasil Penelitian (2019) 
c. Makam

$\begin{array}{llr}\text { Nama File } & \text { : Makam } & \\ \text { Akronim } & : \text { makam.sql } & \\ \text { Fungsi } & : \text { Untuk } & \text { Melihat dan } \\ & \text { Mengelola } & \text { Informasi } \\ & \text { Jenazah, } & \text { Kategori } \\ & \text { Makam dan } & \text { Lahan } \\ & \text { Pemakaman } & \text { yang } \\ & \text { Tersedia } & \\ \text { Tipe File } & \text { : File Master } & \\ \text { Organisasi File } & \text { : Index Sequential } \\ \text { Media } & : \text { Hardisk } \\ \text { Panjang Record } & : \text { 33 Byte } \\ \text { Kunci Field } & : \text { id } \\ \text { Software } & : \text { Mysql }\end{array}$

Tabel 3.

Spesifikasi File Makam

\begin{tabular}{llcl}
\hline Akronim & Tipe & $\begin{array}{c}\text { Panjan } \\
\mathrm{g}\end{array}$ & Ket \\
\hline Id & Integer & 11 & PK \\
\hline id_kategori & Varchar & 11 & \\
\hline $\begin{array}{l}\text { id_detail_jenaza } \\
\text { h }\end{array}$ & Varchar & 11 & \\
\hline Status & Enum & - & \\
\hline Berlaku & Date & - &
\end{tabular}

Sumber: Hasil Penelitian (2019)

C. Rancangan Struktur Navigasi

Struktur navigasi yang digunakan pada website ini adalah struktur navigasi campuran (Composite). Melalui struktur navigasi website ini, terlihat bagaimana isi dan susunan dari sebuah website akan tampil perlahan.

1. Struktur Navigasi Halaman Pengunjung

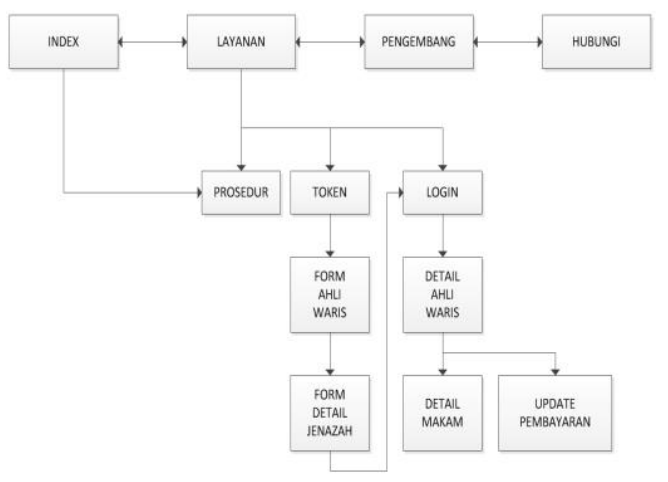

Gambar 10. Struktur Navigasi Halaman Pengunjung
2. Struktur Navigasi Halaman Admin

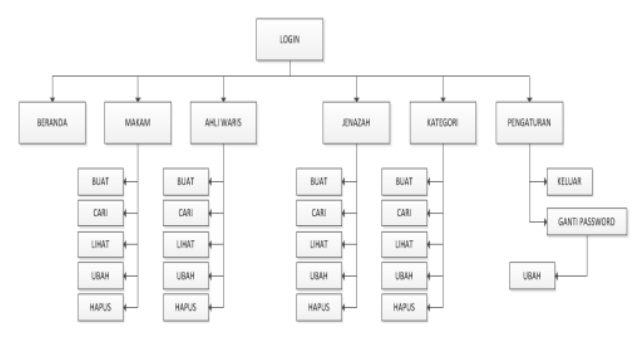

Gambar 11

Struktur Navigasi Halaman Admin

D. Desain Unified Modeling Language

1. Use Case Diagram

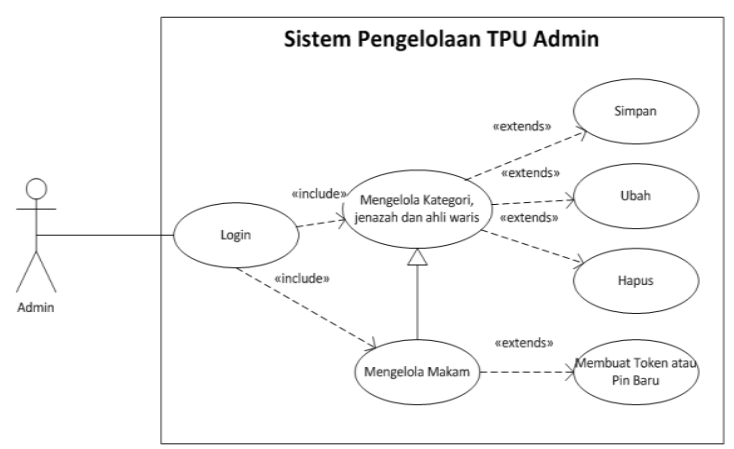

Gambar 12. Use Case Diagram Admin

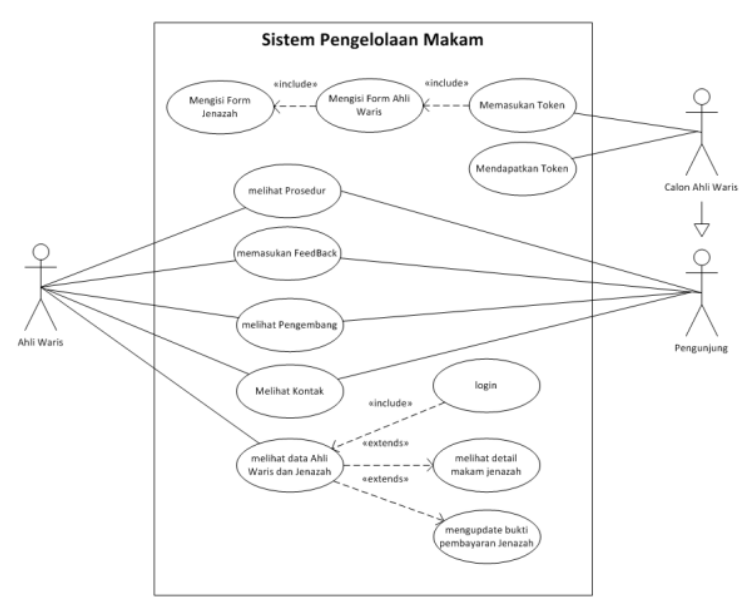

Gambar 13. Use Case Diagram Pengguna 


\section{Activity Diagram}

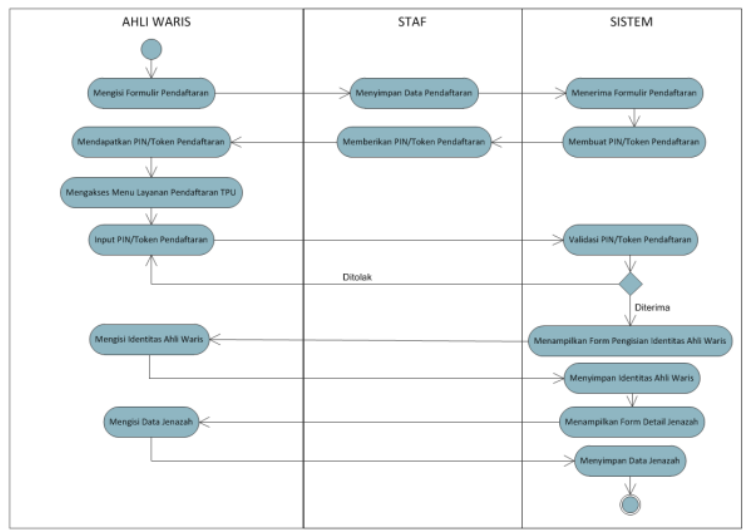

Gambar 14. Activity Diagram Pendaftaran

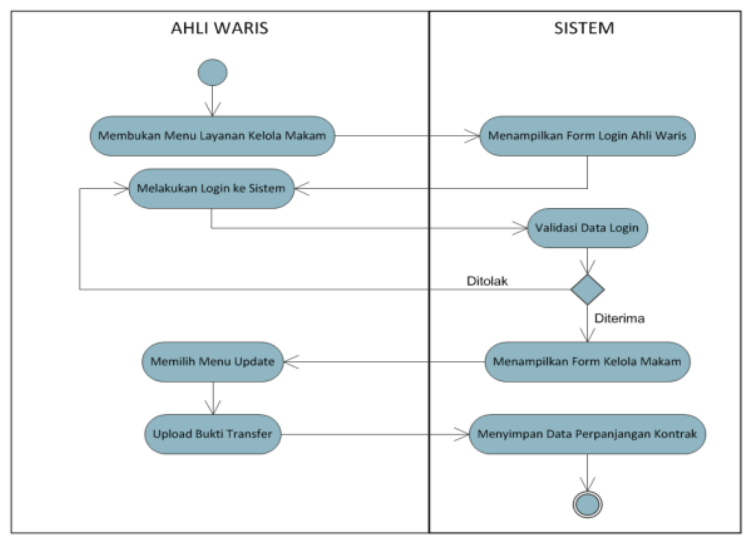

Gambar 15. Activity Diagram Kelola Makam

3. Sequence Diagram

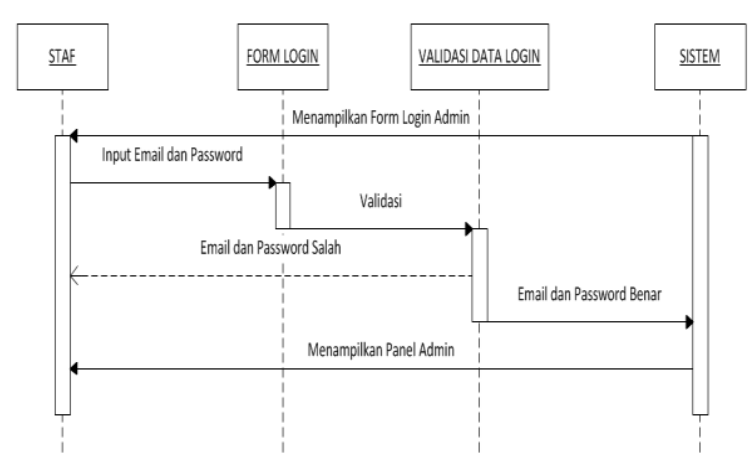

Gambar 16. Sequence Diagram Kelola Makam

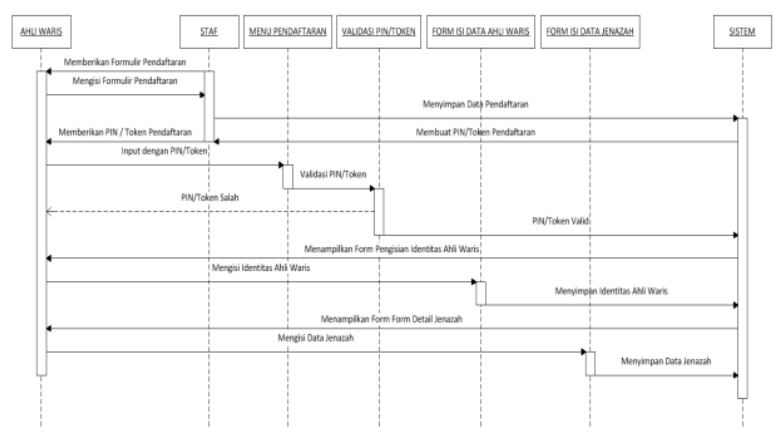

Gambar 17. Sequence Diagram Pendaftaran

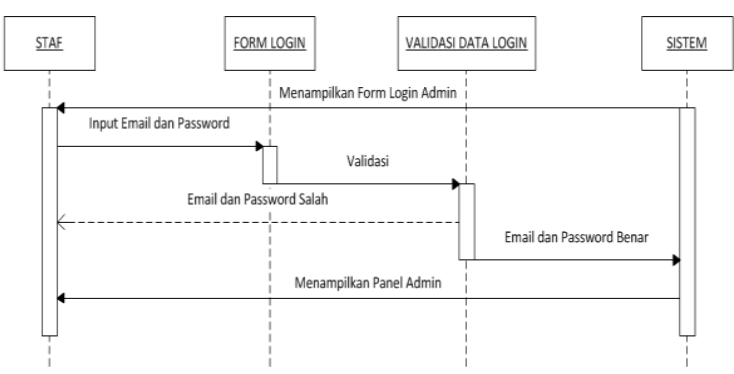

Gambar 18. Sequence Diagram Login Admin

E. Implementasi Antar Muka

1. Halaman Utama/Index

Index (Home) adalah halaman depan dari semua halaman yang ada pada halaman website.

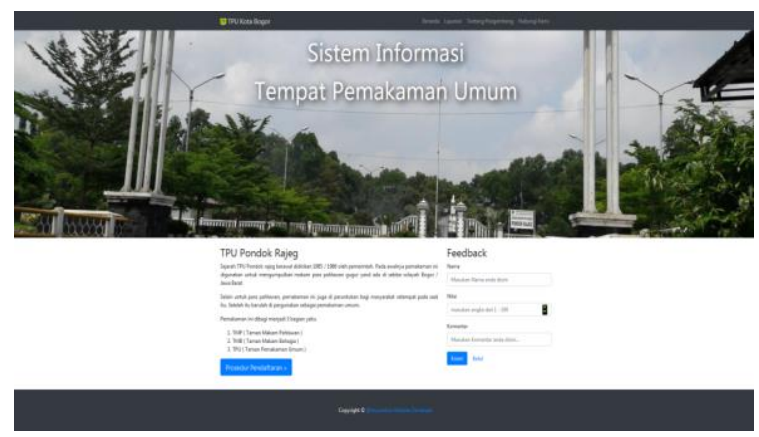

Gambar 19. Halaman Utama (Index)

2. Halaman Layanan

Halaman ini berfungsi untuk menampilkan daftar layanan yang disediakan oleh pihak TPU.

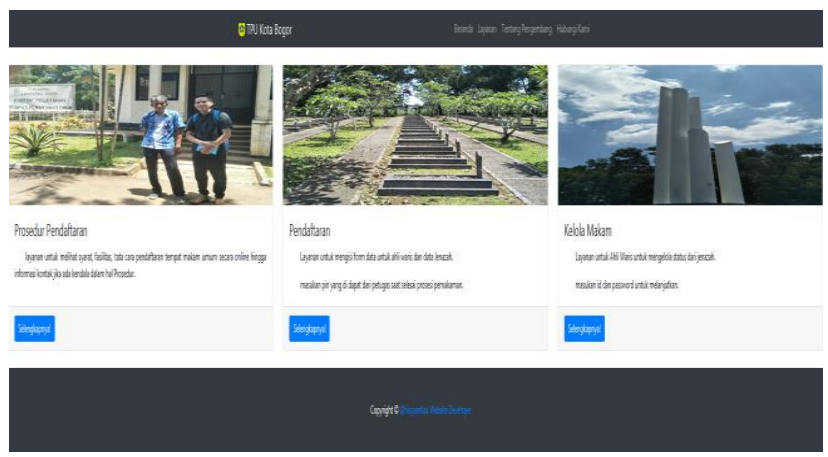

Gambar 20. Halaman Layanan 
3. Halaman Ahli Waris

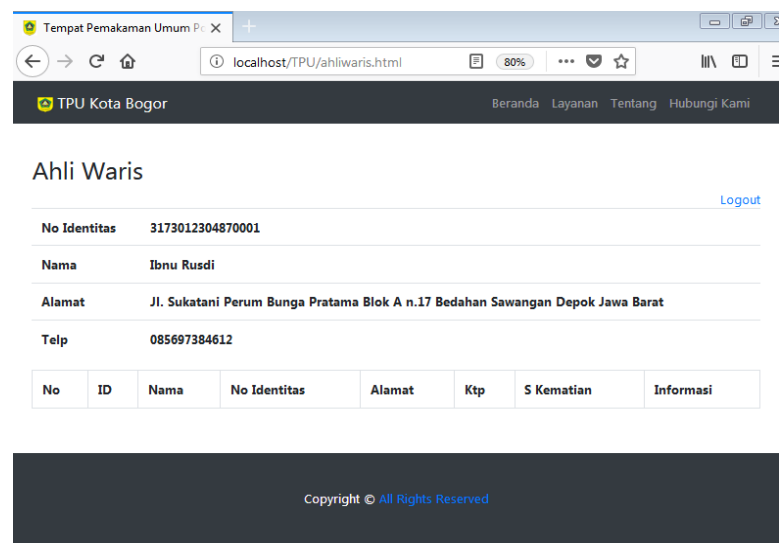

Gambar 21. Halaman Ahli Waris

4. Halaman Login Ahli Waris

\section{전 IPU Kota Bogor}

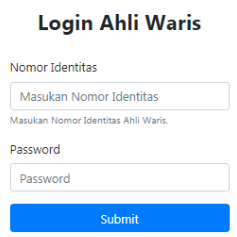

\section{Coppright OA}

Gambar 22. Halaman Login Ahli Waris

F. Implementasi Pengujian

1. Pengujian Terhadap Halaman Pendaftaran Ahli Waris

Tabel 4. Hasil Pengujian Pendaftaran Ahli Waris

\begin{tabular}{|c|c|c|c|c|c|}
\hline $\mathrm{N}$ & $\begin{array}{l}\text { Skena } \\
\text { rio } \\
\text { Pengu } \\
\text { jian }\end{array}$ & $\begin{array}{l}\text { Test } \\
\text { Case }\end{array}$ & $\begin{array}{l}\text { Hasil } \\
\text { yang } \\
\text { diharap } \\
\text { kan }\end{array}$ & $\begin{array}{l}\text { Hasil } \\
\text { Peng } \\
\text { ujian }\end{array}$ & $\begin{array}{l}\text { Kesi } \\
\text { mpul } \\
\text { an }\end{array}$ \\
\hline 1 & $\begin{array}{l}\text { No. } \\
\text { PIN/T } \\
\text { oken } \\
\text { tidak } \\
\text { diisi } \\
\text { kemu } \\
\text { dian } \\
\text { klik } \\
\text { Subm } \\
\text { it }\end{array}$ & $\begin{array}{l}\text { PIN/ } \\
\text { Toke } \\
\mathrm{n}: \\
\text { (Koso } \\
\text { ng) }\end{array}$ & $\begin{array}{l}\text { Sistem } \\
\text { akan } \\
\text { menola } \\
\mathrm{k} \text { dan } \\
\text { menam } \\
\text { pilkan } \\
\text { pesan } \\
\text { "Pin } \\
\text { atau } \\
\text { Token } \\
\text { tidak }\end{array}$ & $\begin{array}{l}\text { Sesu } \\
\text { ai } \\
\text { Hara } \\
\text { pan }\end{array}$ & Valid \\
\hline
\end{tabular}

$$
\text { ada” }
$$

\begin{tabular}{|c|c|c|c|c|c|}
\hline 2 & $\begin{array}{l}\text { Meng } \\
\text { isi } \\
\text { No. } \\
\text { PIN/T } \\
\text { oken } \\
\text { kemu } \\
\text { dian } \\
\text { klik } \\
\text { Subm } \\
\text { it }\end{array}$ & $\begin{array}{l}\text { PIN/ } \\
\text { Toke } \\
\mathrm{n}: \\
\text { Token } \\
\text { (Sala } \\
\text { h) }\end{array}$ & $\begin{array}{l}\text { Sistem } \\
\text { akan } \\
\text { menola } \\
\text { k dan } \\
\text { menam } \\
\text { pilkan } \\
\text { pesan } \\
\text { "Pin } \\
\text { atau } \\
\text { Token } \\
\text { tidak } \\
\text { ada" }\end{array}$ & $\begin{array}{l}\text { Sesu } \\
\text { ai } \\
\text { Hara } \\
\text { pan }\end{array}$ & Valid \\
\hline 3 & $\begin{array}{l}\text { Meng } \\
\text { isi } \\
\text { No. } \\
\text { PIN/T } \\
\text { oken } \\
\text { kemu } \\
\text { dian } \\
\text { klik } \\
\text { Subm } \\
\text { it }\end{array}$ & $\begin{array}{l}\text { PIN/ } \\
\text { Toke } \\
\mathrm{n}: \\
\text { Token } \\
\text { (Bena } \\
\text { r) }\end{array}$ & $\begin{array}{l}\text { Sistem } \\
\text { akan } \\
\text { meneri } \\
\text { ma dan } \\
\text { akan } \\
\text { muncul } \\
\text { formuli } \\
\text { r } \\
\text { pengisi } \\
\text { an data } \\
\text { ahli } \\
\text { waris }\end{array}$ & $\begin{array}{l}\text { Sesu } \\
\text { ai } \\
\text { Hara } \\
\text { pan }\end{array}$ & Valid \\
\hline
\end{tabular}

2. Pengujian Terhadap Halaman Pengisian Data Ahli Waris

Tabel 5. Hasil Pengujian Form Ahli Waris

\begin{tabular}{|c|c|c|c|c|c|}
\hline $\begin{array}{l}\mathrm{N} \\
\mathrm{O}\end{array}$ & $\begin{array}{l}\text { Skena } \\
\text { rio } \\
\text { Pengu } \\
\text { jian }\end{array}$ & $\begin{array}{l}\text { Test } \\
\text { Case }\end{array}$ & $\begin{array}{l}\text { Hasil } \\
\text { yang } \\
\text { diharap } \\
\text { kan }\end{array}$ & $\begin{array}{l}\text { Hasil } \\
\text { Peng } \\
\text { ujian }\end{array}$ & $\begin{array}{l}\text { Kesi } \\
\text { mpul } \\
\text { an }\end{array}$ \\
\hline 1 & $\begin{array}{l}\text { Tidak } \\
\text { Meng } \\
\text { isi } \\
\text { Form } \\
\text { ulir } \\
\text { identi } \\
\text { tas } \\
\text { kemu } \\
\text { dian } \\
\text { klik } \\
\text { Creat } \\
\text { e }\end{array}$ & $\begin{array}{l}\text { No.Id } \\
\text { ent : } \\
\text { (Koso } \\
n g) \\
\text { Nama } \\
: \\
\text { (Koso } \\
n g) \\
\text { Alam } \\
\text { at : } \\
\text { (Koso } \\
n g) \\
\text { Telp : } \\
\text { (Koso } \\
n g) \\
\text { Passo } \\
\text { word } \\
:\end{array}$ & $\begin{array}{l}\text { Sistem } \\
\text { akan } \\
\text { menola } \\
\text { k dan } \\
\text { menam } \\
\text { pilkan } \\
\text { pesan } \\
\text { "The } \\
\text { Field is } \\
\text { Require } \\
\text { d" }\end{array}$ & $\begin{array}{l}\text { Sesu } \\
\text { ai } \\
\text { Hara } \\
\text { pan }\end{array}$ & Valid \\
\hline
\end{tabular}




\begin{tabular}{|c|c|c|c|c|c|}
\hline & & $\begin{array}{l}\text { (Koso } \\
n g) \\
\text { Ulang } \\
\text { i } \\
\text { Passw } \\
\text { ord : } \\
\text { (Koso } \\
n g)\end{array}$ & & & \\
\hline 2 & $\begin{array}{l}\text { Meng } \\
\text { isi } \\
\text { Form } \\
\text { ulir } \\
\text { identi } \\
\text { tas } \\
\text { denga } \\
\text { n } \\
\text { lengk } \\
\text { ap } \\
\text { kemu } \\
\text { dian } \\
\text { klik } \\
\text { Creat } \\
\text { e }\end{array}$ & 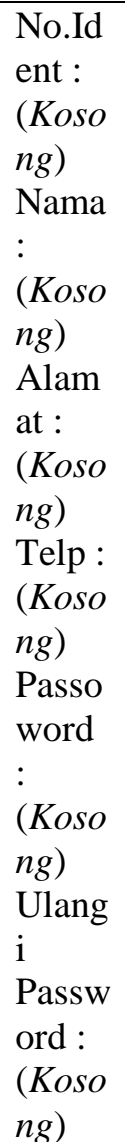 & $\begin{array}{l}\text { Sistem } \\
\text { akan } \\
\text { meneri } \\
\text { ma dan } \\
\text { menam } \\
\text { pilkan } \\
\text { "Formu } \\
\text { lir } \\
\text { pengisi } \\
\text { an data } \\
\text { jenazah } \\
\text { " }\end{array}$ & $\begin{array}{l}\text { Sesu } \\
\text { ai } \\
\text { Hara } \\
\text { pan }\end{array}$ & Valid \\
\hline
\end{tabular}

\section{KESIMPULAN}

Berdasarkan observasi serta analisis yang dilakukan pada lokasi selama penelitian berlangsung, penulis dapat menyimpulkan dengan dibangunnya sistem informasi ini maka diharapkan dapat membantu pendaftar dalam mengetahui ketersediaan lahan pemakaman. Sehingga akan membantu pihak TPU dalam memberikan informasi mengenai ketersediaan lahan pemakaman. Diharapkan dapat membantu pihak TPU dalam mengelola lahan yang tersedia agar dapat termaksimalkan dengan baik. Diharapkan dapat membantu pihak TPU dalam mengelola penumpukan makam berdasarkan hak akses yang dimiliki oleh ahli waris.

\section{REFERENSI}

Frieyadie, \& Kristiana, T. (2016). Rancang Bangun Sistem Informasi Administrasi Tempat Pemakaman Umum (TPU). Konferensi Nasional Ilmu Pengetahuan Dan Teknologi, 2(1), 63-INF.68. Retrieved from http://konferensi.nusamandiri.ac.id/prosiding/i ndex.php/knit/article/view/47

Kadir, A. (2005). Pengenalan sistem Informasi. Yogyakarta: Andi.

Rosa, A. S., \& Shalahuddin, M. (2013). Rekayasa perangkat lunak terstruktur dan berorientasi objek. Bandung: Informatika. Bandung: Informatika Bandung.

Sibero, Alexander F, K. (2013). Web Programming Power Pack. Yogyakarta: Mediakom.

Sofian, E. (2015). Rancang bangun sistem informasi dalam layanan dan pemetaan lokasi pemakamana pada pemakaman umun di wilayah Jakarta, $1(1)$

\section{PROFIL PENULIS}

Ibnu Rusdi Lahir di Jakarta, 23 April 1987 menyelesaikan Program Pasca Sarjana pada STMIK Nusa Mandiri Jakarta tahun 2014, sekarang menjadi Dosen serta bekerja sebagai seorang programmer di Fakultas Ekonomi dan Bisnis (FEB) UI Depok.

Indra Febria Widy Lahir di Jakarta, 20 Febuari 1989 menyelesaikan Program Pascasarjana Universitas Gunadarma di Magister Manajemen Sistem Informasi pada tahun 2015, Mengajar pada program studi Teknik Informatika di STT Cendekia Tangerang Banten.

Hisyam Husein, merupakan mahasiswa lulusan Universitas Bina Sarana Informatika program Diploma tiga dengan program Studi Maanajemen Informatika 